
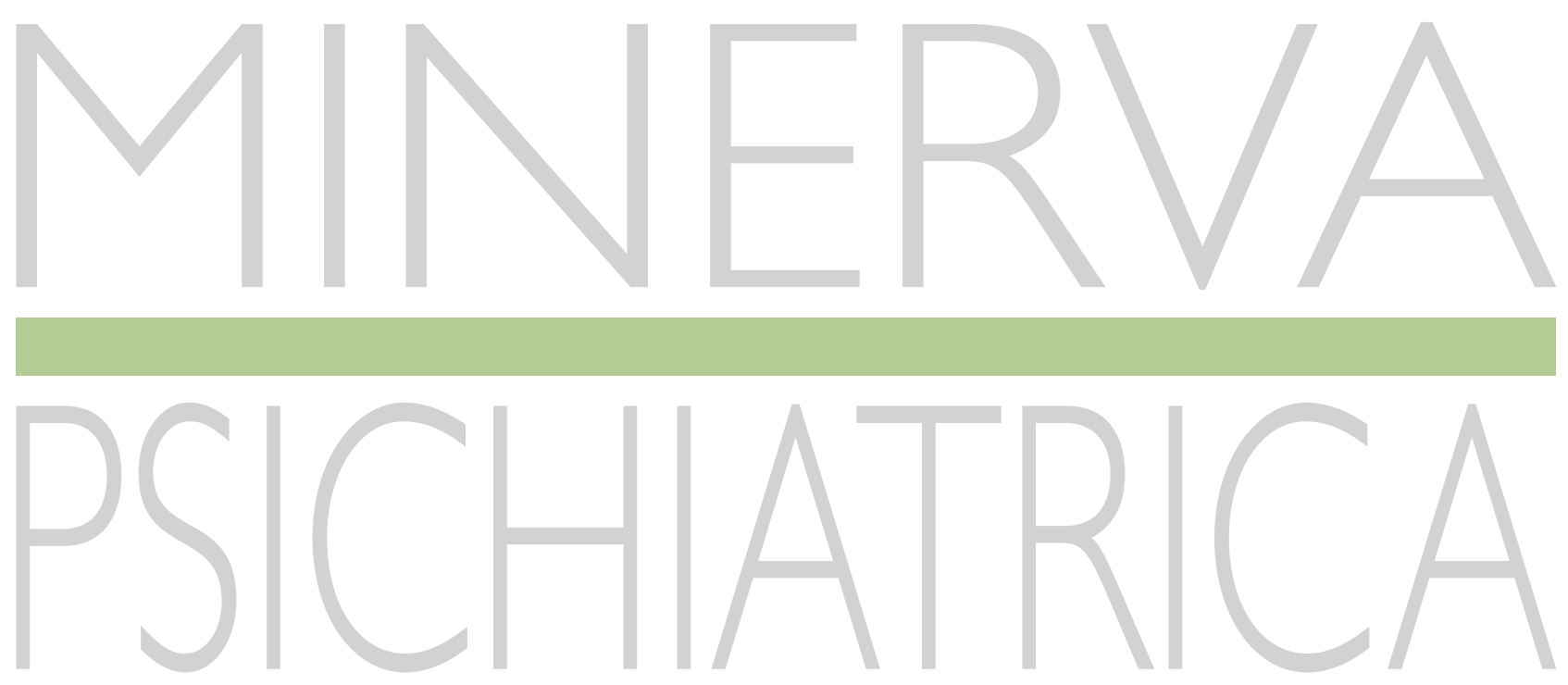

VOLUME 59 . NO.I. MARCH 2018

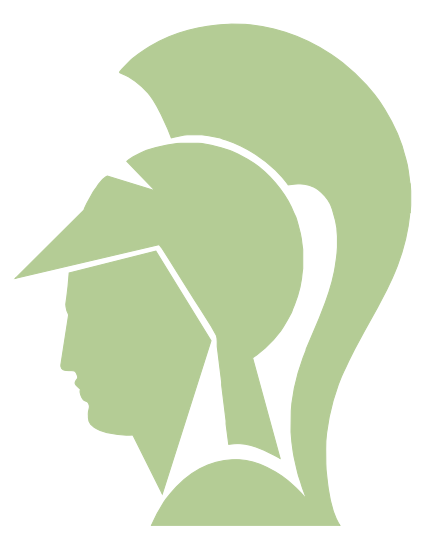

$E D|Z| O N|\cdot M| N E R V A \cdot M E D \mid C A$ 


\title{
Efficacy of animal assisted therapy on people with mental disorders: an update on the evidence
}

\author{
Ludovica SPATTINI 1, Giorgio MATTEI 1, 2, Francesca RAISI ${ }^{3}$, Silvia FERRARI 1, 4 , \\ Luca PINGANI 5, Gian M. GALEAZZI 1,4*
}

1Unit of Psychiatry, Department of Diagnostics, Clinical and Public Health Medicine, University of Modena and Reggio Emilia, Modena, Italy; ${ }^{2}$ School in Labour, Work and Innovation -"Marco Biagi” Department of Economics, University of Modena and Reggio Emilia, Modena, Italy; ${ }^{3}$ Mental Health Area Coordinator at L'Ovile S.C.R.L, Reggio Emilia, Italy; ${ }^{4}$ Center for Neuroscience and Neurotechnology, University of Modena and Reggio Emilia, Modena, Italy; ${ }^{5}$ Unit of Human Resources, Department of Mental Health, Local Health Agency Reggio Emilia, Reggio Emilia, Italy

*Corresponding author: Gian M. Galeazzi, Unit of Psychiatry, Department of Diagnostics, Clinical and Public Health Medicine, University of Modena and Reggio Emilia, Via del Pozzo 71, 41123 Modena, Italy. E-mail: gianmaria.galeazzi@unimore.it

\begin{abstract}
A B S T R A C T
INTRODUCTION: Animal assisted therapy (AAT) is a structured form of animal assisted intervention (AAI), which specifically adopts animals in healthcare services and education facilities, to achieve therapeutic goals. Although such interventions are widely used, nowadays, evidence supporting them is still largely lacking. A previously published review of the literature highlighted some promising effects of AAT on people presenting psychiatric disorders, though the quality of the studies included was generally low. In order to provide an update of recent evidence, the aim of this study was to systematically review randomized controlled trials (RCTs) published since 2000, involving people affected by mental disorders and receiving AAT.

EVIDENCE ACQUISITION: The following databases were searched: CINHAL, EBSCO Psychology and Behavioural Science Collection, PubMed and Web of Science. 115 papers were obtained and screened: 28 were from CINHAL, PsycINFO and Psychology and Behavioural Science Collection altogether, 15 from PubMed and 72 from Web of Science. In addition to this, grey literature and references of already published reviews and meta-analyses on the topic were searched, resulting in the addition of 6 further articles. After screening, 10 RCTs were included in this review.

EVIDENCE SYNTHESIS: Studies involving outpatients were more frequent than those involving inpatients; sample size was generally low. The majority of studies adopted scales routinely used in clinical trials, with a good level of validity and reliability. Five out of ten studies reported significant differences in the main outcomes favouring AAT. Most of the studies did not include any follow-up; yet, where prospective data were available, the benefits of AAT appeared long lasting. Drop-out rates were higher in studies involving outpatients. However, the only trial which enrolled both inpatients and outpatients showed a higher drop-out rate among the inpatients group, possibly due to their more severe psychopathology. CONCLUSIONS: Though a paucity of available studies partly limits our findings, AAT seems to improve empathy, socialization and communication, and to favour therapeutic alliance among patients who have difficulties with therapeutic programs adherence. AAT appears to be a feasible and well-received intervention, potentially with few or no side effects reported. However there is a need for further studies with larger sample sizes and high-quality research standards.

(Cite this article as: Spattini L, Mattei G, Raisi F, Ferrari S, Pingani L, Galeazzi GM. Efficacy of animal assisted therapy on people with mental disorders: an update on the evidence. Minerva Psichiatr 2018;59:54-66. DOI: 10.23736/S0391-1772.17.01958-6) Key words: Animal assisted therapy - Psychiatry - Mental disorders.
\end{abstract}

\section{Introduction}

$\mathrm{D}$ espite their long history and the frequent media attention received, animal-assisted interventions (AAI) are a group of promising complementary practices whose efficacy and specific indications are still to be fully explored. This may be partly due to a possible 
misunderstanding between therapy and other practices offered to people with or without mental disorders, favouring their socialization. In fact, it is important to clarify the distinction between a generic, positive emotional response to animals (which may occur in every experience involving animals) and animal assisted therapy (AAT), since obviously not all experiences that are enjoyed by human beings interacting with animals may be considered therapy. ${ }^{1}$ A review published in 2003 provided 20 different definitions of AAT, ${ }^{2}$ thus supporting the idea that this term was applied to a wide range of programs, even those that would not qualify as therapy in a strict scientific sense.

According to the Delta Society, an international non-profit organization promoting human-animal bond, AAI are goal oriented and structured interventions that intentionally include animals in health, education and human services, to achieve therapeutic gains and improve health and wellness. Among AAI, AAT is a therapeutic goal-directed intervention in which an animal that meets specific criteria is an integral part of the therapeutic process. AAT is delivered by a health professional with specialization and expertise in this field, and has precise therapeutic goals. Key features include specific goals for each individual, a therapeutic process and its measurement. In contrast to AAT, animal assisted activities (AAA), which are also included in AAI, and involve interactions between human beings and animals as well, provide opportunities for motivational, educational, recreational, and other generic benefits, to enhance quality of life, without specific therapeutic goals. In the case of AAA, the intervention is not structured, it may involve volunteers as well as professionals trained in this field, who are not requested to monitor the intervention; also, visit content is not structured. ${ }^{3}$

In recent times, AAIs started to include a new type of intervention, widely used in Norway and in the UK, which is called "Green care" or "Care farming", an umbrella-term covering diverse interventions, all directed at improving or promoting participants' well-being via activities taking place in the natural en- vironment. ${ }^{4-6}$ In this new, recent approach, interaction with farm animals represent a crucial component, with a therapeutic potential that still deserves to be properly researched, since farm animals can be considered in many ways similar to companion animals. In the view of the Delta Society criteria, ${ }^{3}$ farm animal interventions may be classified between AAT and AAA, though actually closer to AAT. For the purposes of this review, farm studies assessing farm animal interventions were included, as detailed below, when the other review inclusion/exclusion criteria were fulfilled.

Even if AAIs, and AATs in particular, are largely adopted in a wide range of therapeutic settings, the reason of the benefits of the interaction with animals is still not completely understood. Several hypotheses have been made. It has been pointed out, for example, that the human-animal bond, especially with dogs, has strong analogies with parent-child attachment: it lasts over time and results in seeking and maintaining proximity to another individual. Animals tend to absorb people's attention, generally in non-threatening ways, helping them to achieve a lower degree of stress and arousal. Moreover, animals respond affectionately to human attentions, and appear capable of increasing tolerance to provocative stimuli through models of non-violent behavioural strategies, ${ }^{7}$ eliciting pro-social behaviours and positive affects, ${ }^{8}$ such as, for example, the ability of human-dog interactions in reducing withdrawal and avoidance behaviors. ${ }^{9}$ According to a recent study about a specific ethogram of elderly-dog interactions, ${ }^{10}$ both a therapeutic and recreational intervention using dogs may decrease the apathetic status of patients living in a nursing home. It is also worth noticing that evidence exists supporting the impact of animal-human being interventions on the cortisol levels of the latter. ${ }^{9}$

A second hypothesis to explain the benefits of AATs considers the role exerted by betaendorphins, oxytocin, prolactin, phenyl ethylamine, dopamine and cortisol in all forms of interactions, making such mediators elective candidates possibly underlying human-animal bonding and its effects on stress and arousal. ${ }^{8}$ 
TABLE I.-Main features of the papers included in the review.

\begin{tabular}{|c|c|c|c|c|c|c|}
\hline $\begin{array}{l}\text { First author } \\
\text { and year of } \\
\text { publication }\end{array}$ & Diagnosis & In/outpatients & $\begin{array}{c}\text { Age } \\
\text { (mean) }\end{array}$ & $\mathrm{F} / \mathrm{M} \%$ & $\begin{array}{l}\text { N. of cases } \\
\text { vs. controls }\end{array}$ & Drop-out rate \\
\hline $\begin{array}{l}\text { Marr et al. } \\
200023\end{array}$ & $\begin{array}{c}\text { Schizophrenia, bipolar } \\
\text { disorder, psychosis } \\
\text { NOS or depression } \\
\text { with history of } \\
\text { alcohol/substance } \\
\text { abuse or other } \\
\text { addictive behavior }\end{array}$ & Inpatients & 41.5 & $30 \% \mathrm{~F}, 70 \% \mathrm{M}$ & 18 vs. 19 & NA \\
\hline $\begin{array}{l}\text { Antonioli et al., } \\
200524\end{array}$ & Depression & Outpatients & 40.2 & $90 \% \mathrm{~F}, 10 \% \mathrm{M}$ & 15 vs. 15 & $13.3 \%$ cases \\
\hline $\begin{array}{l}\text { Berget et al., } \\
200830 \\
\text { Berget et al., } \\
201112\end{array}$ & $\begin{array}{l}\text { Schizophrenia, } \\
\text { schizotypal disorder, } \\
\text { affective disorders, } \\
\text { anxiety and stress- } \\
\text { related disorders, } \\
\text { personality disorder }\end{array}$ & $\begin{array}{c}\text { Both inpatients } \\
\text { and } \\
\text { outpatients }\end{array}$ & 34.7 & $65.6 \% \mathrm{~F}, 34.4 \% \mathrm{M}$ & 41 vs. 28 & $\begin{array}{l}\text { Cases: } 31.7 \% \\
\text { controls: } 6.7 \%\end{array}$ \\
\hline $\begin{array}{l}\text { Villalta et al., } \\
200925\end{array}$ & Schizophrenia & Inpatients & 48.9 & $14.2 \% \mathrm{~F}, 85.8 \% \mathrm{M}$ & 12 vs. 9 & $\begin{array}{c}8.3 \% \text { cases, } 22.2 \% \\
\text { controls }\end{array}$ \\
\hline $\begin{array}{l}\text { Wesley et al., } \\
200928\end{array}$ & Substance abuse & Inpatients & 29.1 & $50.6 \% \mathrm{~F}, 49.4 \% \mathrm{M}$ & 135 vs. 96 & NA \\
\hline $\begin{array}{l}\text { Pedersen et al., } \\
201220\end{array}$ & Depression & Outpatients & 37.5 & $79.3 \% \mathrm{~F}, 20.7 \% \mathrm{M}$ & 16 vs. 13 & $\begin{array}{c}\text { Cases: } 20 \% \text { before } \\
\text { AAT }+25 \% \text { after } \\
\text { AAT; controls } 7 \% \\
\text { before AAT }+7.7 \% \\
\text { after AAT. }\end{array}$ \\
\hline $\begin{array}{l}\text { Majić et al., } \\
201327\end{array}$ & $\begin{array}{c}\text { Major neurocognitive } \\
\text { disorder }\end{array}$ & Inpatients & 81.8 & $72.3 \% \mathrm{~F}, 27.7 \% \mathrm{M}$ & 30 vs. 35 & $\begin{array}{l}\text { Cases: } 14.3 \% \\
\text { Controls: } 16.7 \%\end{array}$ \\
\hline $\begin{array}{l}\text { Alfonso et al. } \\
201529\end{array}$ & Social anxiety & Outpatients & 21.4 & $100 \% \mathrm{~F}, 0 \% \mathrm{M}$ & 5 vs. 6 & NA \\
\hline $\begin{array}{l}\text { Nurenberg et al., } \\
2015^{7}\end{array}$ & $\begin{array}{c}\text { Schizophrenia and } \\
\text { Schizoaffective } \\
\text { disorders }\end{array}$ & Inpatients & 44.4 & $37 \% \mathrm{~F}, 63 \% \mathrm{M}$ & $\begin{array}{c}25(\operatorname{dog}) \\
+24 \text { (horse) } v s . \\
23 \text { (ESS)+18 }\end{array}$ & $\begin{array}{c}\text { Cases: } 4 \% \text { dog, } 4.2 \% \\
\text { horse, } 4.3 \% \text { ESS; } \\
\text { control } 5.6 \%\end{array}$ \\
\hline
\end{tabular}

ICD-10: International Classification of Diseases and Related Health Problems (10 th edition); DSM-IV: Diagnostic and Statistical Manual of Mental Disorders (4th edition); ESS: Enhanched Social Skill; SBS: Social Behavior Scale; 17-HRS: 17 items Hamilton rating scale for depression; BDI: Beck depression inventory; SAS: Zung Self-Rating Anxiety Scale; GSE: Generalized Self-Efficacy Scale; CSS: Coping Strategy Scale; QOLS-N: Quality of Life Scale; PANSS: Positive and Negative Syndrome Scale; LSP: Living Skills Profile; WHOQOL-BREF: Brief World Health Organization Quality of Life Assessment; STO: Satisfaction with Treatment Questionnaire; HAQ-II: Helping Alliance Questionnaire; SSAI: Spielberger State Anxiety Inventory; STAI-SS: State anxiety; CMAI: Cohen Mansfield Agitation Inventory: DMAS: Dementia Mood Assessment Scale; LSAS: Liebowitz Social Anxiety Scale; OAS-M: Overt-Aggression Scale.

In particular, it has been hypothesized that the activation of the oxytocin system could play a central role in many psychological and psychophysiological effects of human-animal interaction in different age groups, possibly affected by medical or psychiatric disorders. The domains that were found to be more positively affected by human-animal interaction were: social attention, behavior, interpersonal interaction and mood; stress-related param- 
Scales used to assess the main outcome
Follow-up
Authors' conclusions
SBS

NA

Patients receiving AAT were found to socialize more with other patients $(\mathrm{P}=0.022)$ and to smile more $(\mathrm{P}=0.025)$; all this improved over the 4 weeks period investigated $(\mathrm{P}=0.04)$.

17-HRS, BDI, SAS NA Depressive symptoms reduced in the treatment group more than among controls, according to HRS and $\mathrm{BDI}$ measures $(\mathrm{P}=0.002$ and $\mathrm{P}=0.006$, respectively). No reduction in anxiety symptoms stemmed out.

GSE, CSS, QOLS-N 6 months Increased self-efficacy $(\mathrm{P}=0.05)$ and coping ability $(\mathrm{P}=0.003)$ in the experimental group; no difference with respect to quality of life.

PANSS, LSP, WHOQOL-BREF, STO

HAQ-II

BDI-IA, STAI-SS, GSE

CMAI, DMAS

LSAS

Frequency of aggressive behavior identified by hospital incident reports, 1:1 observation, seclusion, restraint and OAS-M
NA Patient in the dog group showed significant improvements in the areas of social contact, positive and negative symptoms, and PANNS total score. The perceived quality of life related to social relationships was significantly better, but the non-personal behavior significantly worsened. No differences were found between the two groups of patients in any of the variables assessed at baseline or after the application of the intervention.

NA Patients receiving AAT reported increased therapeutic alliance $(\mathrm{P}<0.001)$.
3 months The intervention group experienced a significant reduction in depression scores and an increase in self-efficacy scores at the end of the intervention, and the participants maintained their gains at the three-month follow-up. In the control group, no significant changes were observed. However, the changes in the scores in the intervention group were not significantly different from those in the control group.

NA In the control group, symptoms of agitation/aggression and depression significantly increased over 10 weeks; in the intervention group, patients receiving combined treatment displayed constant frequency and severity of symptoms of agitation/aggression $(\mathrm{P}<0.05)$ and depression $(\mathrm{P}<0.001)$. Symptom amelioration did not occur in either group. AAT may delay progression of neuropsychiatric symptoms in demented nursing home residents.

6 weeks Compared to controls, patients in the experimental group had significantly greater reductions in social anxiety scores from baseline to immediate postintervention $(\mathrm{P}=008)$ and from baseline to follow-up ( $\mathrm{P}=0.003)$.

NA Interventions were well tolerated; the analyses revealed an intervention group effect $(\mathrm{P}=0.035)$;

post-hoc tests showed specific benefits of equine-assisted psychotherapy $(\mathrm{P}=0.05)$.

Similar AAT effects were found for the incidence of $1: 1$ clinical observation $(\mathrm{P}=0.051)$; post$h o c$ tests suggested benefits of canine-assisted psychotherapy $(\mathrm{P}=0.058)$ as well as equineassisted psychotherapy $(\mathrm{P}=0.082)$. Covariance analyses indicated that staff can predict which patients are likely to benefit from equine-assisted psychotherapy $(\mathrm{P}=0.01)$. eters such as cortisol levels, heart rate and blood pressure; self-reported levels of fear and anxiety; quality of mental and physical health, especially cardiovascular health. ${ }^{11}$ These data and hypotheses suggest that ani- mals play a role in mediating human social interactions, capable of providing people with stress-buffering social support, and reinforcing self-efficacy. ${ }^{12}$

Positive outcomes have been reported for 
AAT with people affected by psychiatric disorders; for example, a reduction in anxiety, depression and pain levels among inpatients, ${ }^{13}$ as well as reduced anxiety, depression and PTSD symptoms among severely traumatized individuals. 10, 14, 15 AAT improved the living skills and the daily activity level of institutionalized middle-aged patients with schizophrenia. ${ }^{10,} 16,17$ It also decreased agitation and increased the quality of social interaction among people affected by major neurocognitive disorders (MND). ${ }^{18}$

In recent years, the number of observational and experimental studies concerning AAT has been steadily growing. However, case reports, case-series, surveys and non-randomized controlled studies still represent the vast majority of the available studies. It is therefore not surprising that recent reviews on the topic commented that overall the methodological level of this growing body of research was not good enough to draw firm conclusions. ${ }^{12,}$ 18-21 Therefore, the aim of the present study was to systematically review randomized only controlled trials (RCTs) comparing AAT to other form of therapy in the literature. The last comprehensive review of the literature covered evidence from 1990 to $2012 ; 21$ it was our intention to provide an update on this topic.

\section{Evidence acquisition}

CINHAL, PsycINFO, Ebsco Psychology and Behavioral Sciences Collection, Web of Science and PubMed databases were searched, using the following key-words: "Animal Assisted Therapy," "Pet Therapy," "Animal Therapy, "Animal Assisted Intervention," Animal Assisted Activity," "Equine therapy," "Mental illness," "Mental disorder," "Psychiatric illness" and "Mental disorders".

The following strings were combined, for the search on PubMed: (("mental disorders" [MeSH Terms] OR "mental disorders" [All Fields]) OR ("mental health" [MeSH Terms] OR "mental health" [All Fields])) AND ("animal assisted therapy" [MeSH Terms] OR "animal assisted therapy" [All Fields] OR "pet therapy" [All Fields]). Using both Mesh terms and free searches on PubMed we tried to minimize the risk of missing not yet indexed articles.

The search was limited to literature published from 31 January 2000 to 30 June 2017. PRISMA guidelines for systematic reviews 22 were followed in designing and carrying on this study.

\section{Inclusion criteria}

Studies were included when the following criteria were met:

- the study enrolled people affected by any psychiatric disorder as defined by the International Classification of Diseases (ICD-9 or ICD-10) and the Diagnostic and Statistical Manual of Mental Disorders (DSM-IV, DSM IV-TR and DSM 5);

— the study adopted an RCT design;

- the study was written in English;

- at least one of the following outcome measures was reported: clinical, cognitive, social, emotional or behavioral, measured by an observer or on a self-reported scale;

- the study was published between 1 January 2000 and 30 June 2017.

\section{Exclusion criteria}

Studies were excluded when one of the following occurred:

- the study did not fall into any of the above listed inclusion criteria;

- the study was focused on AAA;

— the study enrolled people not affected by any psychiatric disorder;

- the study qualitatively explored health professionals' and/or patients' or caregivers' perspectives on AAT.

One Author (LS), with the supervision of another (GMG), reviewed all retrieved records' titles and abstracts to verify eligibility criteria. Where information was insufficient to decide whether to include the study or not, full texts were accessed. Besides searching on widely used databases (detailed above), grey literature was searched as well, by searching the reference lists in all the retrieved articles and other published reviews on this topic.

For each paper included in the review, the 
following information was extracted (Table I, II): title, first author, year of publication, patients' diagnoses, sample size and features, drop-out rates, primary and secondary outcomes, conclusions drawn by researchers, pet-therapist qualification, type of animals involved and training they had, whether an individual or group intervention was administered, its duration, type of interaction, the presence of a follow-up and side effects reported. ${ }^{12,} 20,23-30$

\section{Evidence synthesis}

One hundred and fifteen papers were identified as potentially eligible. Seventy-two were extracted from Web of Science, twenty-eight from CINHAL, PsycINFO and Psychology and Behavioral Science Collection, and fifteen from PubMed. One hundred and eleven papers were excluded after the selection process, leading to only four papers included in the results (Figure 1).

Hand searches carried out on reviews and meta-analyses provided six further studies, that were added to the previous four, thus leading to the inclusion of ten studies in the present review.

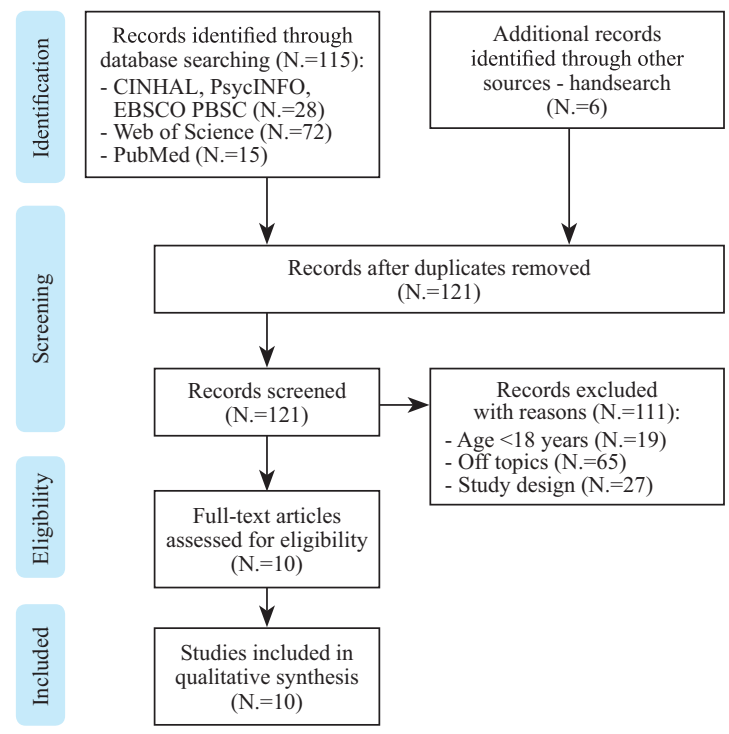

Figure 1.-Flow chart detailing the selection process of papers included in this review.

\section{Diagnoses}

The RCTs included in this review involved people affected by the following psychiatric conditions (according to the ICD-10 and the DSM-IV-TR criteria: schizophrenia, 7, 12, 24, 25 psychosis not otherwise specified (NOS), ${ }^{23}$ schizo-affective disorder, ${ }^{7}$ major depressive disorder, ${ }^{20,23,} 24$ bipolar disorder, ${ }^{23}$ anxiety and stress related disorders, ${ }^{12,}, 24,25$ personality disorders, ${ }^{12,} 24$ substance abuse disorders 23,26 and dementia (MND). ${ }^{26}$

\section{Socio-demographic characteristics}

As Table I shows, the percentage of males and females enrolled in the RCTs varied according to the epidemiology of the disorder investigated (e.g., higher frequencies of women in the studies concerning depression; of men when schizophrenia was investigated). Mean age varied from late adolescence in the case on anxiety disorders (mean age 21 ) to older when major neurocognitive disorder was assessed (mean age 82).

\section{Setting}

Five studies involved inpatients, 7, 23, 25, 27, 28 three outpatients, ${ }^{20,24,29}$ and two involved both inpatients and outpatients. ${ }^{12,30}$

\section{Sample size}

Four out of ten studies included had a small sample size ( $\leq 30$ patients). ${ }^{20}, 24,25,29$ The other studies enrolled more than $30 \mathrm{pa}-$ tients; $7,12,23,27,28,30$ only one study enrolled more than a hundred patients. ${ }^{28}$ The experimental group involved 5-41 patients, while the control group 6-35.7, 20, 23-25, 27-30 There is only one noticeable exception, in which 135 cases were compared with 96 controls. ${ }^{28}$

\section{Outcome measures}

Various rating scales were adopted to assess primary and secondary outcomes, covering the following clinical domains: anxiety (Self- 
Rating Anxiety Scale, Spielberger State Anxiety Inventory, State Scale of the State-Trait Anxiety Inventory, Liebowitz Social Anxiety Scale [LSAS]), depression (Beck Depression Inventory [BDI], Hamilton Rating Scale for Depression [HRSD], Dementia Mood Assessment Scale [DMAS]), symptoms severity (Positive And Negative Syndrome Scale [PANSS]), cognitive impairment (Mini-Mental State Examination [MMSE]), agitation and aggression (Cohen-Mansfield Agitation Inventory [CMAI], Overt Aggression Scale [OAS]), self-efficacy (General Self-Efficacy [GSE]), quality of life (Norwegian Version of the Quality of Life Scale [QOLS-N], World Health Organization Quality of Life Scale abbreviated version [WHOQOL-BREF]), coping, social behavior and living skills (Coping Strategies Scale [CSS], Social Behavior Survival [SBS], Life Skills Profile [LSP]), and therapeutic alliance (revised Helping Alliance Questionnaire [HAQ-II]). The study by Nuremberg et al. ${ }^{7}$ was the only one to consider other variables in addition to rating scale scores, namely frequency of aggressive behavior, need for $1: 1$ observation, seclusion and restraint. Response to intervention was defined by predefined scale score variation pre- and postintervention.

\section{Rate of drop-out}

Drop-out rates were higher in studies involving outpatients, varying from $4 \%$ to $31.7 \%$ in the experimental group, and from up to $22.2 \%$ in the control group (when data were available).20, 24, 29 Differently, studies involving inpatients reported that drop-out rates were higher in the experimental group, varying from $4.2 \%$ to $16.7 \%$ in the experimental group, and from $5.6 \%$ to $22.2 \%$ in the control group. $7,25,26$ In two studies involving inpatients there were no drop-outs. ${ }^{23,28}$

\section{Follow-up}

Only 4 studies 12, 12, 29, 30 included a followup period, varying from 6 weeks to 6 months. The other six studies did not include a followup period, though three of them mentioned some degree of non-structured, postintervention observation or measurements. ${ }^{7,24,27}$

\section{Findings with respect to the diagnostic group}

MAJOR NEUROCOGNITIVE DISORDER (1 STUDY)

Among people affected by MND, AAT appeared to be well accepted, though findings from the only RCT ${ }^{18}$ do not support its use with this type of patients. People affected by MND in the experimental group received an AAT that involved dogs, and were compared with people receiving treatment as usual (TAU). Individual sessions involved a professional dog therapist, and were delivered weekly over a period of 10 weeks. Clinical symptomatology did not decrease, either in the control and the experimental group; rather, it increased, especially with respect to agitation $(\mathrm{P}<0.001)$ and depressive symptoms $(\mathrm{P}<0.001)$. The authors attributed the findings to a worsening in the clinical conditions of people involved (due to disorder progression) rather to failure of the experimental treatment or TAU.

\section{MAJOR DEPRESSIVE DISORDER (2 STUDIES)}

To be included in the two RCTs on MDD, patients had to have a score $\geq 14$ on the BDI (20) or $\geq 11$ on the HRS-17.24 Pedersen et al., ${ }^{20}$ reported that the experimental group, involving farm animals, experienced a reduction in depression scores and an increase in selfefficacy scores: findings were still present at three-month follow-up. Despite these positive results, there was no significant difference to controls. ${ }^{20}$

In the second study on MDD, ${ }^{24}$ patients in the experimental group were assigned to an animal care programme with dolphins, while controls were received an outdoor nature programme (i.e. coral reef snorkelling). After treatment, the experimental group reported decreased depressive symptoms (17-HRS $\mathrm{P}=0.002$; $\mathrm{BDI}$, $\mathrm{P}=0.006$ ), while no significant difference was observed in the group with anxiety symptoms.

Although both studies reported a clinically significant improvement in depressive 
symptoms after being exposed to AAT, only one RCT ${ }^{23}$ found this different to controls. It is worth mentioning that the two studies involved people with different severity of MDD. In fact, in the study by Pedersen et al. ${ }^{20}$ cases presented mean BDI scores indicating moderate depression, while in the study by Antonioli et al. ${ }^{24}$ cases presented a mean HRS indicating mild and moderate depression (40\% and $60 \%$ of cases respectively). It is possible that this difference in depression severity of the samples recruited may have partly determined different outcomes.

The dolphin-based intervention by Antonioli et al. ${ }^{24}$ was delivered by means of high frequency group sessions, corresponding to a total intervention time of ten hours; in contrast, farm animal therapy was generally individually administered twice a week, corresponding to a total intervention time of fifty-four hours. With respect to the way the intervention was implemented, namely individual vs. group, it may be interesting to note that the study involving group animal therapy produced more robust findings, in a sample made up of people with mild to moderate MDD, possibly helping them address issues of social withdrawal and isolation, which are frequent in depressive disorders. It is also remarkable that in the Antonioli and Reveley's study 24 the improvement in depressive symptoms occurred quite rapidly, within 2 weeks, and most patients provided a self-report evaluation indicating high perceived levels of wellbeing up to three months after the intervention, even if this was not a formal follow-up.

Since only two RCTs were found concerning MDD, reporting only partially consistent results, more research seems needed to draw firm conclusions about the efficacy of AAT in this group of patients.

\section{ANXIETY DISORDERS (1 STUDY)}

The Project Stride Study 29 compared a cognitive-behavioural equine-assisted intervention designed to address social anxiety in young women with a control group who received no treatment. The experimental group showed greater reduction of social anxiety levels from baseline to immediate postintervention $(\mathrm{P}=0.008)$ and from baseline to followup $(\mathrm{P}=0.003)$ compared to the control group. Change scores did not differ significantly between the two groups from immediate-post intervention to follow-up. Also, the type of controls used (i.e., people receiving no treatment), the absence of an arm of the study receiving placebo and another arm receiving a standard, evidence-based therapy for anxiety disorders (e.g., CBT only, or medications such as SSRI) are strong limitations of this study. There is a substantial need for RCTs of high study design quality to address the issue of AAT efficacy in anxiety disorders.

\section{SubstANCE USE DISORDER (1 STUDY)}

In the only RCT available on this topic, ${ }^{28}$ inpatients affected by substance use disorder were randomly assigned to an experimental group. Results indicate that the therapeutic alliance is enhanced with the addition of a therapy dog, in the hypothesis that this could decrease patients' stress, and foster healthy attachment to the animal.26,31 People in the control group received the same group therapy, without dog. This study primarily aimed at understanding how AAT affects therapeutic alliance. Interestingly, a significant difference was found between mean HAQ-II ratings $(\mathrm{P}<0.001)$ in the two groups, thus indicating an impact of AAT on therapeutic alliance, and encouraging its use in this field, as well as the design of other future research. ${ }^{28}$ Despite this, it is important to notice that the following subgroups reported results similar to controls: people affected by dual diagnosis, people with social services involvement and people seeking treatment for alcohol problems (e.g. alcohol use disorder).

\section{SCHIZOPHRENIA SPECTRUM AND RELATED DISOR- DERS (1 STUDY)}

Though previous studies reported encouraging findings concerning the use of AAT with patients with schizophrenia, ${ }^{16,25,32,33}$ only one study was found eligible for the present 
TABLE II.-Features of the AAT assessed by the studies included in the review.

\begin{tabular}{lccc}
\multicolumn{1}{c}{ First author } & Pet therapist qualification & Pet species & Pet training type \\
\hline $\begin{array}{l}\text { Marr } \text { et al., } \\
2000^{23}\end{array}$ & AAT Technician & Dogs, rabbits, ferrets and guinea & Not specified \\
Antonioli et al., & Dolphin trainer & pigs & Not specified \\
200524 & & Dolphins
\end{tabular}

Berget et al., 200830

Berget et al., 201112

Villalta et al., 200925

Wesley et al., 200928

Pedersen et al., 201220

Majić et al.,

201327

Alfonso et al., 201529

Nurenberg et al., Certified equine and dog therapist 20157
Farmers. Only two of them had earlier experience with psychiatric patients

Trained psychologist

Doctoral level therapist

Farmers

Dog therapy guide

Two research associates and a clinical psychologist were trained by doctoral level researchers experienced in cognitive-behavioral therapy intervention and equine-assisted activities
Farm and domestic animals (cows, sheep, horses, poultry, pigs, rabbits, cats, dogs)

Dogs

Dogs

Dairy cattle (most farms had also companion animals)

Dogs

Horses

Horses and dogs
Not specified

Certified therapy dog

Certified therapy International registration as a Delta Pet Partner by Delta Society

Not specified

Educated therapy dog

Not specified

Horses tested and credentialed by Delta Society, dogs not specified review, ${ }^{25}$ in which an integrated psychological treatment was developed, i.e. an intervention focused on cognitive and social functioning aimed at inpatients with persistent schizophrenia. The experimental group received this intervention in the presence of a dog, and reported significant improvements in the area of social contact $(\mathrm{P}=0.041)$, positive $(\mathrm{P}=0.005)$ and negative $(\mathrm{P}=0.005)$ symptoms at the PANSS, and PANSS total score $(\mathrm{P}=0.014)$. Moreover, the perceived quality of life related to social relationships was significantly higher in the experimental group $(\mathrm{P}=0.024)$, though a slight worsening in their non-personal behavior was noticeable $(\mathrm{P}=0.049)$. Controls had significant beneficial changes in positive $(\mathrm{P}=0.027)$ and general $(\mathrm{P}=0.046)$ symptoms and total PANSS score $(\mathrm{P}=0.027)$, but no significant differences were found between the two groups with respect to any variables assessed at baseline or after intervention application. ${ }^{25}$

Overall the study does not favor the animal treatment, although the fact that the experimental group showed a decrease in negative symptoms, notoriously resistant to change, appears to be worth further exploration.

\section{STUDIES ON MIXED COMORBID DIAGNOSES (4 STUDIES)}

Four studies out of the ten included patients with mixed comorbid diagnoses i.e. the presence of more than one psychiatric disorder in an individual patient.

In the first study, by Marr et al. study, ${ }^{23}$ people enrolled were all inpatients present- 


\begin{tabular}{|c|c|c|c|}
\hline Type of interaction between patient and animal & Individual or group session & Duration of intervention & Side effects \\
\hline $\begin{array}{l}\text { Interaction with the animals, by holding them, } \\
\text { petting them and/or playing with them }\end{array}$ & Group & $\begin{array}{l}4 \text { weeks, daily (Mon-Fry), } \\
1 \text { h/day }\end{array}$ & NA \\
\hline $\begin{array}{c}\text { Playing, swimming and taking care of the } \\
\text { animals }\end{array}$ & Group & $\begin{array}{l}2 \text { weeks, daily (Mon-Fry), } \\
1 \text { h/day }\end{array}$ & $\begin{array}{l}\text { No side effects } \\
\text { were noted, } \\
\text { though possible } \\
\text { accidental injuries } \\
\text { were pointed out }\end{array}$ \\
\hline $\begin{array}{l}\text { Physical contact, communication, moving, } \\
\text { feeding, go/stand/run or sit down, cleaning, } \\
\text { milking, receiving instructions }\end{array}$ & $\begin{array}{l}\text { Mainly individual ( } 1 \text { or } 2 \\
\text { visitors at time) }\end{array}$ & $\begin{array}{l}12 \text { weeks, twice a week, } \\
3 \text { hours }\end{array}$ & NA \\
\hline Interaction with the dog, e.g. by repeating orders & Group & $\begin{array}{l}25 \text { sessions, twice a week, } \\
45 \text { minutes each ( } 12.5 \\
\text { weeks) }\end{array}$ & NA \\
\hline $\begin{array}{l}\text { Physical touch. The dog had a repertoire of } \\
\text { "tricks" in order to interact with patients }\end{array}$ & Group & $\begin{array}{l}14 \text { sessions of } 1 \text { hour each, } \\
\text { over } 3 \text { weeks }\end{array}$ & NA \\
\hline $\begin{array}{l}\text { Grooming, mucking, feeding, taking care of } \\
\text { calves, milking and physical contact }\end{array}$ & $\begin{array}{c}\text { Mainly individual ( } 1 \text { or } 2 \\
\text { visitors at time) }\end{array}$ & $\begin{array}{l}12 \text { weeks, twice a week, } \\
1.5 \text { to } 3 \mathrm{~h}\end{array}$ & Allergic reactions \\
\hline $\begin{array}{c}\text { Verbal interaction, stroking, petting and throwing } \\
\text { the ball }\end{array}$ & Individual & $\begin{array}{l}10 \text { weeks, once a week, up } \\
\text { to } 45 \text { minutes }\end{array}$ & $\begin{array}{l}\text { Fearful reaction } \\
\text { (3 patients) }\end{array}$ \\
\hline $\begin{array}{l}\text { Grooming, hoof picking, read horse body } \\
\text { language, lead through obstacles, ride }\end{array}$ & Individual and group & $\begin{array}{l}6 \text { sessions, once a week, } \\
\text { session from } 2 \text { to } 2.5 \mathrm{~h}\end{array}$ & NA \\
\hline $\begin{array}{l}\text { Horses: ground exercises, interaction, no riding } \\
\text { Dogs: grooming, leading, directing }\end{array}$ & Group & $\begin{array}{l}10 \text { weeks, once a week, } \\
40-60 \text { minute }\end{array}$ & $\begin{array}{l}\text { No adverse } \\
\text { effects requiring } \\
\text { medical or } \\
\text { psychiatric } \\
\text { attention }\end{array}$ \\
\hline
\end{tabular}

ing the following conditions: schizophrenia (48\%), bipolar disorder (27\%), psychosis NOS (18\%) and depression (7\%). For each patient, researchers evaluated activity, responsiveness to surroundings, socialization and helpfulness with others, interaction, smiles and expression of pleasure, speech production, patient's self-care and demeanour. People in the experimental group showed higher levels of interaction $(\mathrm{P}=0.022)$, smiles and signs of pleasure $(\mathrm{P}=0.025)$, and all these indicators improved over a 4 -week period $(\mathrm{P}=0.04)$. Over a longer period, socialization, helpfulness and cooperativeness improved significantly in the experimental group, but this was not different from the control group. An important limitation of this study was that raters were not blind.

The second and third study on psychiatric comorbidity are by Berget et al.,12, 30 and involve the same population of in- and outpatients with schizophrenia and schizotypal disorder $(37.7 \%)$, affective disorders $(24.4 \%)$, anxiety and stress related disorders $(11.1 \%)$, personality and behavior disorders $(24.4 \%)$. In both studies, the experimental group received a farm AAT, while controls received TAU. The first paper published by this group of authors 12 focused on AAT effects on self-efficacy, coping ability and quality of life. When compared to controls, patients in the experimental group showed improved self-efficacy, from preintervention to follow-up $(\mathrm{P}=0.05)$ and from end of intervention to follow-up $(\mathrm{P}=0.02)$; also, improved coping abilities were noticeable from preintervention to follow-up $(\mathrm{P}=0.003)$. The second paper of this research group ${ }^{30}$ focused on the efficacy 
of AAT on levels of anxiety and depression. In the experimental group, anxiety did not decrease significantly during the intervention, but was significantly reduced at 6-month followup when compared with baseline $(\mathrm{P}=0.002)$ and with end of the experimental treatment $(\mathrm{P}=0.004)$. Interestingly, no differences were found between patients in the experimental group and controls during the intervention period, but a significant reduction in anxiety was noticeable 6 months after the end of the intervention only in patients in the experimental group, possibly suggesting a delayed effect.

The last paper included in this review with mixed diagnostic groups 7 compared the efficacy of equine-assisted therapy, canine-assisted therapy, enhanced social skills intervention and TAU among inpatients with aggressive or regressive behaviors affected by different psychiatric conditions (mainly schizophrenia and schizoaffective disorders $76 \%$ ). Less violent incidents were significantly noticeable in the equine-assisted group $(\mathrm{P}=0.035)$, compared to increased or unchanged levels for other groups. The need for 1:1 clinical observation due to violent behavior reduced in the groups with canine and equine therapies, while no differences were found as to what coercive measures were concerned (Table II).7, 12, 20, 23-25, 27-30

\section{AAT features}

Table II reports the main features of the AATs used in the studies included in this review. Most of them are specified therapists' qualification. Only the studies conducted in a farm environment 12, 20,30 involved people without apparent formal training in AAT supervising/facilitating the patient-animal interaction.

Animals involved in AAT were commonly dogs, ${ }^{7}$ horses,${ }^{4}$ cattle and small farms animals. Only one study involved aquatic animals: dolphins.

The majority of authors introduced the animals specifying their name, age, breed, size, and previous experience in therapy, 4 studies $7,25,27,28$ provided a specific qualification of the animals (certification or official registration).

In all studies, the interaction with animals included verbal and non-verbal communication, with particular emphasis on physical contact (grooming, petting, stroking, etc.).

Group sessions were more frequently used rather than individual sessions. Individual sessions were preferred in farm environment 12, 20, 30 and when inpatients with MND were involved. ${ }^{27}$

The average duration of interventions was $7.9( \pm 4.2)$ weeks, frequency $2.7( \pm 1.8)$ sessions per week and session duration 85.6 $( \pm 50.4)$ minutes, with a total mean intervention time of $24.3( \pm 22.8)$ hours.

Side effects were mentioned only in four studies, whilst two studies reported allergic or fearful reactions. ${ }^{20,27} \mathrm{~A}$ further two studies reported that no side effects were noticeable. 7,24 The remaining studies did not report on the presence of side effects, a relevant limitation that needs to be addressed by future research.

\section{Discussion}

To our knowledge this is the first review focusing only on RCTs of AAT with people with mental disorders. A previous review, that considered RCTs published from 1990 to 2012 concerning the use of AAT in all fields of medicine, concluded that the quality of the studies included was generally low, not apt to perform a meta-analysis; the same review conceded that AAT might be a promising type of intervention for people with mental disorders who like animals. ${ }^{34}$

Our review reaches similar conclusions, ${ }^{32}$ and is also consistent with the appraisal of qualitative studies. ${ }^{12,18,20,34}$ All these studies called for an improvement in the quality of research in AAT, e.g. with respect to the need for longer intervention periods, follow-up, bigger sample size, detailed side-effects report and drop-out assessment. Also, the use of intention-to-treat analyses and evaluation of costeffectiveness were suggested.

The fact that only ten papers met adequate criteria for being assessed and included in this review is an interesting finding per se, suggesting that AAT is currently receiving relatively little attention. 
The studies we reviewed involved more outpatients than inpatients, and generally had a small sample size. They used valid and reliable scales, with only one noticeable exception (the SBS). Half of the studies produced data at least partially favoring AAT. 7, 23, 24, 28, 29 Yet, the absence of follow-up in the majority of them is a clear limitation.

Professionals who delivered the intervention were generally well qualified. When farm animals were used, farmers remained close to the patients during the intervention to ensure their safety. ${ }^{12,}$ 20, 30 Animals used in AAT are mostly dogs and horses, probably due to their intrinsic docility and trainability, all noticeable features since interaction and physical contact with animals were the main ingredient of AAT in the studies we reviewed. This aspect seems particularly important when considering the integration of treatment as usual with AAT (as happened in several studies here included), given that in the common patienttherapist relationship close contact and touching is generally considered problematic and/ or inappropriate, as well as possibly symptomatic. On the contrary, touching animals may represent a very positive and safe experience for people who show impaired interaction and socialization.

The fact that the majority of studies involved group interventions rather than individual sessions may be due to cost/effectiveness reasons, but the possibility to take advantage of therapeutic factors related to group therapy and dynamics should be considered, as well.

With respect to duration and frequency of AAT sessions, a wide range was noticeable, making it difficult to provide indications concerning this particular aspect.

The paucity of contraindications to AAT (except impaired gait or fear of animals) and side effects reporting in most of the reviewed studies merits attention. It is possible that the lack of prospective recording may lead to under-reporting of these important aspects.

Few studies specified how the psychiatric diagnoses were established, 7, 12, 20, 27, 30 this being an issue that future research should definitely improve. Also, only two studies adopted an intention to treat analysis, ${ }^{20,} 24$ a blindness of raters was guaranteed only in 5 studies. ${ }^{8,15-}$ 19, 27, 29 None of the studies provided a clear cost-effective analysis of the intervention.

\section{Conclusions}

AAT emerged as a well-accepted, apparently safe intervention, leading to positive outcomes in a wide range of psychiatric conditions. AAT may foster increased socialization and communication skills, and reduce anxiety and depressive symptoms. Benefits in terms of decreased positive and negative symptoms of psychosis were also reported. Notably, AAT may help at increasing therapeutic alliance among patients who have difficulties with therapeutic programs adherence. Yet, the paucity of RCTs available and their quality suggests a cautious approach and the need of further research.

\section{References}

1. Beck AM, Katcher AH. A new look at pet-facilitated therapy. J Am Vet Med Assoc 1984;184:414-21.

2. LaJoie KR. An evaluation of the effectiveness of using animals in therapy. Thesis dissertation. Psy D Spalding University; 2003.

3. Fine AH. Handbook on Animal-Assisted Therapy: Theoretical Foundations and Guidelines for Practice. Third edition. Cambridge, MA: Academic Press, 2010.

4. Hine R, Peacock J, Pretty J. Care farming in the UK: Contexts, benefits and links with therapeutic communities. Ther Communities 2008;29:245-60.

5. Sempik J, Hine R, Wilcox D. Green Care: A Conceptual Framework, A Report of the Working Group on the Health Benefits of Green Care, COST Action 866, Green Care in Agriculture. Loughborough, UK: Centre for Child and Family Research, Loughborough University; 2010.

6. Haubenhofer DK, Elings M, Hassink J, Hine RE. The development of green care in western European countries. Explore N Y N 2010;6:106-11.

7. Nurenberg JR, Schleifer SJ, Shaffer TM, Yellin M, Desai PJ, Amin R, et al. Animal-assisted therapy with chronic psychiatric inpatients: equine-assisted psychotherapy and aggressive behavior. Psychiatr Serv 2015;66:80-6.

8. Odendaal JSJ, Meintjes RA. Neurophysiological correlates of affiliative behaviour between humans and dogs. Vet J Lond Engl 2003;165:296-301.

9. Cirulli F, Borgi M, Berry A, Francia N, Alleva E. Animal-assisted interventions as innovative tools for mental health. Ann Istituto Super San 2011;47:341-8.

10. Berry A, Borgi M, Terranova L, Chiarotti F, Alleva E, Cirulli F. Developing effective animal-assisted intervention programs involving visiting dogs for institutionalized geriatric patients: a pilot study. Psychogeriatr Off J Jpn Psychogeriatr Soc 2012;12:143-50.

11. Beetz A, Uvnäs-Moberg K, Julius H, Kotrschal K. Psychosocial and psychophysiological effects of humananimal interactions: the possible role of oxytocin. Front Psychol 2012;3:234. 
12. Berget B, Ekeberg Ø, Pedersen I, Braastad BO. AnimalAssisted Therapy with Farm Animals for Persons with Psychiatric Disorders: Effects on Anxiety and Depression, a Randomized Controlled Trial. Occup Ther Ment Health 2011;27:50-64.

13. Nepps P, Stewart CN, Bruckno SR. Animal-Assisted Activity: Effects of a Complementary Intervention Program on Psychological and Physiological Variables. J EvidBased Complement Altern Med 2014;19:211-5.

14. O'Haire ME, Guérin NA, Kirkham AC. Animal-Assisted Intervention for trauma: a systematic literature review. Front Psychol 2015;6:1121.

15. O'Haire ME, McKenzie SJ, Beck AM, Slaughter V. Animals may act as social buffers: Skin conductance arousal in children with autism spectrum disorder in a social context. Dev Psychobiol 2015;57:584-95.

16. Barak Y, Savorai O, Mavashev S, Beni A. Animal-assisted therapy for elderly schizophrenic patients: a one-year controlled trial. Am J Geriatr Psychiatry 2001;9:439-42.

17. Kovács Z, Kis R, Rózsa S, Rózsa L. Animal-assisted therapy for middle-aged schizophrenic patients living in a social institution. A pilot study. Clin Rehabil 2004;18:483-6.

18. Bernabei V, De Ronchi D, La Ferla T, Moretti F, Tonelli $\mathrm{L}$, Ferrari B, et al. Animal-assisted interventions for elderly patients affected by dementia or psychiatric disorders: A review. J Psychiatr Res 2013;47:762-73.

19. Maber-Aleksandrowicz S, Avent C, Hassiotis A. A Systematic Review of Animal-Assisted Therapy on Psychosocial Outcomes in People with Intellectual Disability. Res Dev Disabil 2016;49-50:322-38.

20. Pedersen I, Martinsen E, Berget B, Braastad B. Farm Animal-Assisted Intervention for People with Clinical Depression: A Randomized Controlled Trial. Anthrozoos Multidiscip J Interact People Anim 2012;25:149-60.

21. Nimer J, Lundahl B. Animal-Assisted Therapy: A MetaAnalysis. Anthrozoos Multidiscip J Interact People Anim 2007;20:225-38.

22. Moher D, Liberati A, Tetzlaff J, Altman DG, Group TP. Preferred Reporting Items for Systematic Reviews and Meta-Analyses: The PRISMA Statement. PLOS Med 2009;6:e1000097.

23. Marr CA, French L, Thompson D, Drum L, Greening G,
Mormon J, et al. Animal-Assisted Therapy in Psychiatric Rehabilitation. Anthrozoös 2000;13:43-7.

24. Antonioli C, Reveley MA. Randomised controlled trial of animal facilitated therapy with dolphins in the treatment of depression. BMJ 2005;331:1231.

25. Villalta-Gil V, Roca M, Gonzalez N, Domènec E, Cuca, Escanilla A, et al. Dog-Assisted Therapy in the Treatment of Chronic Schizophrenia Inpatients. Anthrozoös 2009;22:149-59.

26. Fine AH. Animals and Therapists: Incorporating Animals in Outpatient Psychotherapy. In: Handbook on AnimalAssisted Therapy. Burlington, MA: Academic Press; 2006.

27. Majić T, Gutzmann H, Heinz A, Lang UE, Rapp MA. Animal-assisted therapy and agitation and depression in nursing home residents with dementia: a matched casecontrol trial. Am J Geriatr Psychiatry Off J Am Assoc Geriatr Psychiatry 2013;21:1052-9.

28. Wesley MC, Minatrea NB, Watson JC. Animal-Assisted Therapy in the Treatment of Substance Dependence. Anthrozoös 2009;22:137-48.

29. Alfonso SV, Alfonso LA, Llabre MM, Fernandez MI. Project Stride: An Equine-Assisted Intervention to Reduce Symptoms of Social Anxiety in Young Women. Explore N Y N 2015;11:461-7.

30. Berget B, Ekeberg Ø, Braastad BO. Attitudes to animalassisted therapy with farm animals among health staff and farmers. J Psychiatr Ment Health Nurs 2008;15:576-81.

31. Fine AH. Incorporating animal-assisted therapy into psychotherapy: guidelines and suggestions for therapists. In: Handbook on Animal-Assisted Therapy. Third edition. San Diego, CA: Academic Press; 2010.

32. Nathans-Barel I, Feldman P, Berger B, Modai I, Silver H. Animal-assisted therapy ameliorates anhedonia in schizophrenia patients. A controlled pilot study. Psychother Psychosom 2005;74:31-5.

33. Barker SB, Dawson KS. The Effects of Animal-Assisted Therapy on Anxiety Ratings of Hospitalized Psychiatric Patients. Psychiatr Serv 1998;49:797-801.

34. Kamioka H, Okada S, Tsutani K, Park H, Okuizumi H, Handa S, et al. Effectiveness of animal-assisted therapy: A systematic review of randomized controlled trials. Complement Ther Med 2014;22:371-90.

Conflicts of interest.-The authors certify that there is no conflict of interest with any financial organization regarding the material discussed in the manuscript.

Acknowledgements.- Authors wish to thank Mansur Quraishi (London, UK) for offering invaluable help in revising form and language of earlier drafts of this review.

Manuscript accepted: December 11, 2017. - Manuscript received: December 11, 2017. 